\title{
Acute Management of Traumatic Brain Injury
}

\author{
Michael A. Vella, MD, MBA ${ }^{1}$, Marie Crandall, MD, MPH, FACS ${ }^{2}$, and Mayur B. Patel, MD, \\ MPH, FACS ${ }^{3}$
}

\author{
${ }^{1}$ Chief Resident in General Surgery, Department of Surgery, Section of Surgical Sciences, \\ Vanderbilt University Medical Center, Medical Center North, CCC-4312, 1161 21st Avenue South, \\ Nashville, TN 37232-2730, michael.a.vella@vanderbilt.edu 2Professor of Surgery, Division of \\ Acute Care Surgery, Department of Surgery, University of Florida, Jacksonville, 655 West 8th \\ Street, Jacksonville, FL 32209, Marie.crandall@jax.ufl.edu ${ }^{3}$ Assistant Professor of Surgery, \\ Neurosurgery, Hearing \& Speech Sciences, Division of Trauma, Surgical Critical Care, and \\ Emergency General Surgery, Department of Surgery, Section of Surgical Sciences, Center for \\ Health Services Research, Vanderbilt Brain Institute, Vanderbilt University Medical Center, 1211 \\ 21st Avenue South, Medical Arts Building, Suite 404, Nashville, TN 37212 , \\ mayur.b.patel@vanderbilt.edu
}

\section{Synopsis}

\begin{abstract}
Traumatic brain injury (TBI) is a leading cause of death and disability in trauma patients. As the primary injury cannot be undone, management strategies must therefore focus on preventing secondary injury by avoiding hypotension and hypoxia and maintaining appropriate cerebral perfusion pressure (CPP), which is a surrogate for cerebral blood flow (CBF). Cerebral perfusion pressure can be maintained by increasing mean arterial pressure (MAP), decreasing intracranial pressure (ICP), or both. MAP can be increased through a combination of pressors in the euvolemic state, although the ideal fluid in TBI patients is unknown. The goal should be euvolemia and avoidance of hypotension. Elevated intracranial pressure can be treated through an algorithmic approach utilization simple bedside maneuvers, hyperosmolar therapy, cerebral spinal fluid (CSF) drainage as well as pentobarbital coma and decompressive craniectomy in refractory cases. Mass lesions may require operative evacuation depending on size, exam findings, and ICP measurements. Although CPP may not be an ideal surrogate for cerebral blood flow and metabolic delivery, other modalities have not gained widespread use due to paucity of strong data. Other factors that deserve important consideration in the acute management of TBI patients are venous thromboembolism, stress ulcer, and seizure prophylaxis as well as nutritional and metabolic optimization.
\end{abstract}

\footnotetext{
Correspondence to: Mayur B. Patel.
}

Publisher's Disclaimer: This is a PDF file of an unedited manuscript that has been accepted for publication. As a service to our customers we are providing this early version of the manuscript. The manuscript will undergo copyediting, typesetting, and review of the resulting proof before it is published in its final citable form. Please note that during the production process errors may be discovered which could affect the content, and all legal disclaimers that apply to the journal pertain.

Disclosures:

The authors have no other disclosures relevant to this manuscript. 


\section{Keywords}

Traumatic brain injury; intracranial hypertension; secondary injury; hyperosmolar therapy; barbiturate coma; decompressive craniectomy

\section{Epidemiology}

Trauma is the leading cause of death in individuals aged 1-45, with traumatic brain injury (TBI) responsible for the majority of these, over 50,000 deaths per year in the United States. ${ }^{1-3}$ TBI can be clinically stratified into mild, moderate, and severe based on the Glasgow Coma Scale Score (GCS), with associated permanent disability rates of 10, 60, and $100 \%$, respectively, and overall mortality rates of $20-30 \% .3,4$ The economic impact is over $\$ 80$ billion in the US alone according to the most recent CDC data. ${ }^{3,5}$ This article focuses on the prehospital, emergency department, and intensive care unit (ICU) management of TBI.

\section{Mechanism and Pathophysiology}

Traumatic brain injuries can result from both blunt and penetrating mechanisms. Falls (35\%) and motor vehicle collisions (17\%) are the most common, with motor vehicle collisions leading to majority of fatalities. Gunshot wounds to the head are the most lethal of injuries, but, due to overall incidence, result in less total deaths. 3,4

The primary insult to the brain cannot be undone and results in brain tissue damage, impaired cerebral blood flow (CBF) regulation, and alterations in brain metabolism with upregulation of inflammatory mediators, oxidative stress, and vasospasm. These processes ultimately lead to cell death and generalized brain edema. ${ }^{6}$

The Monro-Kellie hypothesis holds that the total intracranial volume is made up of brain tissue, cerebral spinal fluid (CSF), venous blood, and arterial blood. CBF remains constant under normal conditions via cerebral autoregulatory mechanisms over a range of blood pressures. When one compartment is increased, by a hematoma for example, there must be a compensatory decrease in another compartment in order to prevent intracranial hypertension. Cerebral perfusion pressure (CPP) is a surrogate for CBF. CPP is defined as mean arterial pressure (MAP) - intracranial pressure (ICP). A decrease in CPP implies a decrease in CBF, although this association is not perfect. Decreased CBF ultimately leads to ischemia and hypoxia and worsening of the initial brain insult. ${ }^{2,5}$ The goal of TBI management is to prevent this secondary insult.

\section{Avoidance of Secondary Injury}

Currently, we cannot reverse the initial insult causing a TBI, referred to as the primary injury. Hypotension, previously defined as systolic blood pressure $<90 \mathrm{mmHg}$, and hypoxia, defined as a $\mathrm{PaO}_{2} \$ 60 \mathrm{mmHg}$, have been associated with doubling of mortality in head injured patients. ${ }^{7,8}$ Early studies from the 1970 's showed an association between "systemic insults", mainly hypotension, hypoxia, and hypercarbia, and increased mortality, suggesting an important role for trauma center transfer in patients with severe TBI. ${ }^{9}$ Management 
strategies must therefore focus on the prevention of secondary injury (i.e. hypoxia, hypotension) through maintenance of adequate $\mathrm{CBF}$ and prevention of hypoxia.

\section{Prehospital Management}

Consistent with all phases of TBI management, prehospital strategies should focus on preventing secondary brain injury. In one study, patients with moderate to severe TBI transferred to level I trauma centers via helicopter who had secondary insults (either SBP $<90 \mathrm{mmHg}$ or $\mathrm{SpO}_{2}<92 \%$ ) were found to have a $28 \%$ mortality, compared to $20 \%$ of patients without such insults. Prehospital hypoxia in these same patients was associated with a significant increase in mortality, and there was no difference in hypoxic episodes between patients intubated vs. those not intubated in the field. ${ }^{10}$ Similarly, prehospital rapid sequence intubation performed by paramedics in head injured patients with GCS $<9$ was associated with an increase in mortality. This result may be associated with the transient hypoxia during the prehospital procedures, excessive over-ventilation causing hypocarbia, vasoconstriction, and impaired CBF, and longer scene times. ${ }^{11}$ This body of work implies a need for rapid transfer to definitive care and a focus on more basic airway strategies to maintain oxygenation in head injured patients.

Several studies have also evaluated the use of hypertonic saline in the prehospital arena as a means to improve CPP by decreasing ICP and increasing MAP. In a 2004 study by Cooper, et. al., patients with severe TBI (GCS <9) and hypotension (SBP <100 mmHg) were assigned to either rapid administration of $7.5 \%$ saline or a similar bolus of Ringer's lactate by paramedics. Neurologic function at 6 months did not differ between the two groups, although mean sodium levels in the treatment group was only $149 \mathrm{mEq} / \mathrm{L}^{12} \mathrm{~A}$ multicenter randomized clinical trial in 2010 by Bulger, et. al. looked at patients with severe TBI (GCS <9) not in hypovolemic shock. Patients were administered either $7.5 \%$ saline $/ 6 \%$ dextran 70 , $7.5 \%$ saline alone, or $0.9 \%$ saline. Neurologic outcome at 6 months and survival did not differ among groups. ${ }^{13}$ At this time, prehospital use of hypertonic saline cannot be recommended.

\section{Emergency Department Management}

The initial management of patients with TBI is identical to that of all trauma patients, focusing on the Advanced Trauma Life Support (ATLS) principles of management of airway, breathing, and circulation, followed by a rapid neurologic exam and exposure of the patient with prevention of hypothermia. ${ }^{14}$

The airway should be secured according to local protocols. Induction agents such as propofol should be carefully used, possibly in conjunction with induction inotropes, given the risk of systemic hypotension with impaired CBF. Ketamine is an attractive agent in trauma patients given its favorable hemodynamic profile. Despite theoretical risks, a systematic review of ketamine use in TBI suggests that ketamine does not increase ICP ${ }^{15}$

Breathing should be optimized to maintain oxygenation and prevent ventilatory dysfunction, as extremes in $\mathrm{CO}_{2}$ can lead to cerebral vasoconstriction, vasodilation, and have been shown to be predictors of morbidity and mortality. ${ }^{8}$ Hyperventilation is used by some providers to 
acutely decrease ICP through hypocarbic vasoconstriction, despite evidence showing an association between even brief periods of hyperventilation and increased mediators of secondary brain injury in areas adjacent to injured brain tissue as well as local reductions in cerebral perfusion. ${ }^{16-18}$ This strategy should be used with caution, and perhaps only employed to acutely combat signs of active herniation while initiating more definitive treatment.

Circulation should be maintained to prevent hypotension and maintain CBF. There is a known coagulopathy related to head injury likely related to tissue factor release coupled with hypoperfusion, which may be exacerbated by a pure crystalloid resuscitation. A balanced blood product resuscitation has been shown to be beneficial in trauma patients, ${ }^{19-21}$ and may be extended to TBI patients. Uncrossmatched packed red blood cells are an initial resuscitative fluid choice that is often used in hypotensive trauma patients, with a goal to maintain SBP $₫ 0 \mathrm{mmHg}$ in patients suspected of having a TBI. The concept of permissive hypotension does not apply to patients with known or suspected TBI, and normal physiologic blood pressure parameters should be targeted in this population.

During the "disability" component of the primary survey, a rapid neurologic evaluation is performed. The evaluation focuses on the pupillary exam, assesses for lateralizing signs suggesting a mass lesion with increased ICP, and calculates a GCS score to stratify the TBI severity. The patient should then be exposed to evaluate for injury and rapidly covered to prevent hypothermia. A more detailed examination is performed during the secondary survey. Agents such as hypertonic saline and/or mannitol (discussed in more detail below) can be given during this initial resuscitation if physical exam findings suggest a neurologic decline, significant head injury, or lateralizing neurologic exam.

Following the initial resuscitation, patients suspected of having a TBI usually undergo a noncontrasted head CT scan depending on the presence of other injuries that require more urgent attention. Recent level II recommendations from the Eastern Association for the Surgery of Trauma (EAST) suggest obtaining a head CT scan in patients "that present with suspected brain injury in the acute setting if it is available". In cases where rapid CT scanning is not available, providers can consider using one of the various criteria for determining need for additional imaging, such as the Canadian CT Head Rule and the New Orleans Criteria. ${ }^{22,23}$

\section{Operative Management of Mass Lesions}

Recent guidelines recommend surgical evacuation for epidural hematomas (EDH) $>30 \mathrm{~cm}^{3}$ regardless of GCS. Surgical evacuation should be considered for patients with EDH and GCS $<9$, clot thickness $>15 \mathrm{~mm}$, midline shift $>5 \mathrm{~mm}$ or focal neurologic deficits. Epidural hematomas $<30 \mathrm{~cm}^{3},<15 \mathrm{~mm}$ thick, with $<5 \mathrm{~mm}$ shift in patients with GCS $>8$ and no focal deficits can be watched with close observation and serial imaging (with repeat scan 6-8 hours from prior). ${ }^{24}$ Evacuation should be considered for subdural hematomas $(\mathrm{SDH})>1 \mathrm{~cm}$ or those associated with midline shift $>5 \mathrm{~mm}$, a GCS $<8$ with rapid decline, or ICP $<20$ $\mathrm{mmHg} .{ }^{25}$ Patients with parenchymal lesions and progressive neurologic decline, mass effect, refractory ICH, GCS scores of 6-8 with frontal or temporal contusions $>20 \mathrm{~cm}^{3}$, midline 
shift of at least $5 \mathrm{~mm}$ and/or compression of cisterns, or lesion volume $>50 \mathrm{~cm}^{3}$ should be considered for decompression. ${ }^{26}$ Early studies found a significant mortality benefit if evacuation is performed within four hours from injury. ${ }^{27,28}$ The STITCH (Trauma) trial, a Surgical Trial in Traumatic intraCerebral Hemorrhage, which compared 6 month outcomes in trauma patients with intraparenchymal hemorrhage randomized to early operative evacuation ( $<12$ hours) to conservative management, was stopped early at 170 patients due to recruitment issues but showed a mortality benefit in patients who underwent early operative intervention. ${ }^{29}$

\section{ICU Circulatory Considerations}

Systolic blood pressure should be maintained $\searrow 90 \mathrm{mmHg}$ through use of fluids and pressors, although the Brain Trauma Foundation (BTF) provides Level III recommendations for higher thresholds, depending on age. ${ }^{30,31}$ The ideal fluid for patients with traumatic brain injury is unknown, although fluids should be administered judiciously and hypotonic fluids avoided to prevent volume overload and potential worsening of cerebral edema. In a posthoc analysis of head injured patients in the SAFE (Saline versus Albumin Fluid Evaluation) study, those who received albumin had higher mortality rates compared to those who received saline. ${ }^{32}$ Although packed red blood cells are often used as the initial fluid in traumatically injured patients, transfusing to a hemoglobin $>10 \mathrm{~g} / \mathrm{dL}$ has been associated more adverse events and no improvement in 6-month neurological outcome in TBI patients compared with those transfused to a restrictive threshold of $7 \mathrm{~g} / \mathrm{dL} .{ }^{33}$

Brain-injured patients may require reversal of anticoagulant and antiplatelet agents, as the pre-hospital use of these medications may increase mortality after TBI. ${ }^{34-36}$ The most recent Eastern Association for the Surgery of Trauma (EAST) Guideline suggests that all elderly patients on pre-hospital systemic anticoagulation who are suspected of having a head injury should undergo rapid head CT evaluation. ${ }^{37}$ It is also recommended that head-injured patients on warfarin should undergo rapid (within 2 hours of presentation) reversal of warfarin with fresh frozen plasma (FFP) and vitamin K. ${ }^{37,38}$ McMillian, et. al. propose a simple algorithm for management of patients on aspirin, clopidogrel, and warfarin who are suspected of having a head injury. If intra-cranial hemorrhage is identified on an immediate head CT in a patient on warfarin, 4 units of type-specific FFP and $10 \mathrm{mg}$ of IV vitamin $\mathrm{K}$ are administered with a goal INR of <1.6. If the patient is on an antiplatelet agent, a 10 pack of type-specific platelets is administered. ${ }^{39}$ Prothrombin complex concentration (PCC) and desmopressin can also be considered to reverse warfarin anticoagulation and antiplatelet agents, respectively. ${ }^{40-42}$ Novel anticoagulants, both direct thrombin inhibitors (dabigatran) and factor Xa inhibitors (rivaroxaban, apixaban, edoxaban), pose a unique challenge given a lack of reversal options. The reader is referred to a review article from 2013 that suggests an approach to the management of the bleeding patient on a novel anticoagulant, which may be extrapolated to the head-injured patient. In addition to treating coagulopathies with FFP and platelets when appropriate, four-factor or activated PCC can be administered, and dialysis can be considered for patients on dabigatran if feasible. ${ }^{43}$ Idarucizumab, a monoclonal antibody fragment, has been found to rapidly reverse the effects of dabigatran in patients with serious bleeding and may have a role in the trauma patient. ${ }^{44}$ Early administration of tranexamic acid (TXA), an antifibrinolytic agent, has been shown to reduce all cause 
mortality and death due to bleeding in trauma patients with significant bleeding. ${ }^{45}$ The CRASH-2 Intracranial Bleeding Study showed that neither moderate benefits nor moderate harmful effects of TXA can be excluded in bleeding trauma patients with traumatic brain injury. ${ }^{46}$ The CRASH-3 Trial is designed to quantify the effects of early administration of TXA on death and disability in patients with TBI and is currently underway. ${ }^{47}$

\section{ICU Management of Intracranial Hypertension}

Figure 1 presents a simple algorithm for the management of patients with severe TBI used at the authors' institution and focuses mainly on the management of elevated ICP. The neurosurgical service is consulted upon identification of a TBI, and mass lesions are evacuated if indicated. Basic labs are ordered to evaluate for coagulopathy and seizure prophylaxis is started (discussed below). Patients with moderate to severe TBI are admitted to the intensive care unit (ICU) for ongoing resuscitation and prevention of secondary brain injury. A 2013 study found that acute care surgeons can effectively manage patients with mild TBI without neurosurgical evaluation, although this cannot be firmly extrapolated to patients with moderate or severe TBI, and we suggest neurosurgical consultation for any intracranial hemorrhage, irrespective of neurologic function. ${ }^{48}$

As noted in Figure 1, patients admitted to the intensive care unit should have optimization of oxygen, ventilation, and SBP. Simple maneuvers like loosening of the cervical collar, raising the head of bed $>30$ degrees or maintaining a reverse Trendelenburg position (if no contraindication), and optimizing sedation and analgesia can decrease ICP, although some of these may not improve CBF or CPP. ${ }^{49}$ Blood products can be given to keep INR $<1.5$ and platelets $\geq 100,000$ to prevent further intracranial bleeding, although these are arbitrary hemostatic thresholds and may be influenced by pre-injury antiplatelet/anticoagulants, availability of thromboelastography (TEG), neurologic changes, imaging changes, and/or institutional culture.

\section{ICP Monitoring}

Consideration should be given to placement of an ICP monitor in patients with severe TBI. External ventricular drains (EVD), which are placed in the lateral ventricle and connected to a pressure monitor, can also be used for continuous or intermittent drainage of CSF as a means to decrease ICP. Open or continuous EVD have been associated with better ICP lowering than intermittent or closed EVD, although EVD monitors have not been shown to be superior to intraparenchymal ICP monitors. Intraparenchymal monitors are placed directly into brain tissue but may not accurately measure pressure in the CSF due to pressure gradients that occur after TBI. ${ }^{50-52}$ Both device types measure intracranial pressure, and the calculated CPP is used as a surrogate for $\mathrm{CBF}$, and, by extension, brain oxygenation and metabolic supply.

The Brain Trauma Foundation (BTF) recommends (level IIB) ICP monitoring in patients with severe TBI (GCS <9) and abnormal CT scan to reduce 2 week and in-hospital mortality. It is also recommended that CSF drainage be considered to reduce ICP in patients with a GCS $<6$ within the first 12 hours of injury. General goals are to maintain an ICP $<20$ 
and CPP between 50-70, depending on autoregulatory status. Values higher have been associated with respiratory complications and poor outcomes. ${ }^{30,53}$

In a study evaluating compliance with the 3rd edition of the BTF ICP monitoring guidelines, patients who underwent ICP monitoring had less in-hospital mortality and less herniationrelated mortality but longer ICU and hospital length of stay compared to patients who did not undergo ICP monitoring. ${ }^{54}$ In 2,134 patients with severe TBI, those treated with an a protocol-based ICP monitoring algorithm had significantly less mortality compared to patients treated without an ICP monitor (19\% vs. $33 \%$ ), although no mention is made regarding goal ICP/CPP or the treatment modalities used to reduce ICP. ${ }^{55}$ In contrast, the Benchmark Evidence from South American Trials: Treatment of Intracranial Pressure (BEST:TRIP) multicenter randomized clinical trial from 6 hospitals and 324 ICU patients with severe TBI, ICP monitoring was not superior to care based on imaging and physical exam. ${ }^{56}$

CPP and ICP are inexact surrogates for cerebral blood flow given the heterogeneity of traumatic brain injury and an unknown optimal CPP for a given patient, suggesting a role for more multimodal monitoring. ${ }^{57,58}$ Transcranial Doppler ultrasonography is a non-invasive technique that measures $\mathrm{CBF}$ velocity, where differences in $\mathrm{CBF}$ velocity are used to estimate differences in CBF. Jugular bulb monitoring of arteriovenous oxygen content difference $\left(\mathrm{AVDO}_{2}\right)$ utilizes a central line placed in the jugular bulb and a peripheral arterial line. The difference in oxygen content between blood entering and leaving the brain can be calculated to provide a global picture of supply and demand. Cerebral microdialysis is a technique whereby a catheter is placed in the penumbra, or area adjacent to the traumatized brain, and used to evaluate the local biochemical environment. Brain tissue oxygen tension can be measured with a parenchymal probe but is highly dependent on placement, provides a very focal measurement of oxygenation, and may not be an appropriate surrogate for global perfusion. ${ }^{52}$ Given lack of sufficient data, routine use of novel neuromonitoring strategies is not commonplace at this time. In its most recent guidelines, the BTF provides level III recommendations for measurement of $\mathrm{AVDO}_{2}$, the optimization of which has been associated with favorable outcomes 6 months after injury. It is recommended to avoid $\mathrm{AVDO}_{2}<50 \% .^{30,59-61}$

As noted in Figure 1, patients undergo EVD placement if criteria are met and the procedure is technically feasible. If ICP remains elevated, continuous CSF drainage is employed. If the $\mathrm{CPP}$ remains low, MAP is increased using a combination of volume expansion and pressors, as discussed later.

\section{Hyperosmolar Therapy}

Intracranial hypertension can be managed with hyperosmolar therapy, although there is no strong evidence about the appropriate agent, administration (i.e., continuous versus bolus), or timing. Hypertonic saline (HTS) of various concentrations and mannitol are the primary pharmacologic agents used to reduce ICP, perhaps through reduction in blood viscosity, improved microcirculatory flow, and decreased cerebral blood volume. 
A BTF Class II rated retrospective study using data from the BTF's TBI-trac New York State Database evaluated patients treated with a single agent for ICP reduction. HTS administrations were typically $3 \%$ concentrations, and mannitol administrations were $20 \%$ concentration. Bolus HTS therapy was more effective at lowering ICP and ICU length of stay. There was no statistically significant difference in two-week mortality. ${ }^{62}$

The 2016 BTF guidelines indicate there is insufficient evidence on clinical outcomes to support recommendations on the use or type of hyperosmolar therapy. ${ }^{30}$ Our protocol as noted in Figure 1 is to use $3 \%$ saline at $30-50 \mathrm{ml} / \mathrm{hr}$ and $250-500 \mathrm{ml}$ intermittent boluses every four to six hours with lab draws to maintain serum sodium at $145-160 \mathrm{mEq} / \mathrm{L}$ and osmolality <320. Mannitol is used as a second line agent and/or considered when hypervolemia is present. If CPP remains less than 60, MAP can be increased with a combination of fluid resuscitation and pressors, with phenylephrine often used. ${ }^{31}$

\section{Barbiturate Coma}

Patients without mass lesions amenable to intervention and refractory ICP $>20 \mathrm{mmHg}$ can be treated with barbiturates. In one multicenter study, patients with severe TBI refractory to basic maneuvers, hyperosmolar therapy, and intraventricular catheter drainage were treated with a continuous pentobarbital drip with EEG monitoring. Pentobarbital coma was found to effectively improve CPP. Forty percent of patients survived to discharge and 68\% of patients had good functional outcomes in one year or more after injury. ${ }^{63}$ Other investigators call into question the benefit of pentobarbital therapy, especially in light of systemic effects like hypotension. ${ }^{64}$ Ultimately, the 2016 BTF guidelines do not advocate barbiturate therapy as prophylaxis against intracranial hypertension. But, when treating refractory intracranial hypertension with barbiturates, avoiding hemodynamic instability is recommended. ${ }^{30}$

We suggest that patients with ICP 21-29 for at least 30 minutes, 30-39 for at least 15 minutes, or 40 or more for 1 minute who have met sodium and osmolality thresholds (i.e., on maximal hyperosmolar therapy) are candidates for pentobarbital coma. Pentobarbital is bolused at $10 \mathrm{mg} / \mathrm{kg}$ over 30 minutes, followed by a $5 \mathrm{mg} / \mathrm{kg} / \mathrm{hr}$ infusion for 3 hours, after which time it is titrated to $1 \mathrm{mg} / \mathrm{kg} / \mathrm{hr}$ and adjusted as needed with an EEG burst suppression goal of $2-5$ bursts per minute while monitoring for significant side effects (i.e. hypotension $)^{65}$.

\section{Decompressive Craniectomy}

Decompressive craniectomy (DC) has been shown to reduce ICP and can be considered if ICP is refractory to other measures, although some may consider it earlier in the treatment algorithm. ${ }^{24,26,66,67}$ In the DECRA (Decompressive craniectomy in diffuse traumatic brain injury) randomized clinical trial, bifrontotemporoparietal decompressive craniectomy in patients with diffuse traumatic brain injury and refractory ICH resulted in lower ICP and shorter ICU length of stay. However, DC was associated with unfavorable long-term neurologic function, as measured by the Extended Glasgow Outcome Scale (GOSE), and similar mortality at 6 months compared to patients receiving standard treatment. ${ }^{68}$ 
The most recent 2016 guidelines from the BTF do not recommend bifrontal DC as a means to improve neurologic outcomes based on these results, although they do recommend a large frontoparietal DC over a smaller one. ${ }^{30}$ The reader should know this BTF recommendation was released prior to the results of the more recently published RESCUEicp study (Randomized Evaluation of Surgery with Craniectomy for Uncontrollable Elevation of Intracranial Pressure). In the RESCUEicp randomized clinical trial, patients with refractory ICP $>25 \mathrm{mmHg}$ for 1-12 hours despite multimodal therapy were assigned to either DC or standard management. The primary outcome was the 6-month GOSE. Patients undergoing DC had higher rates of vegetative state, but lower rates of mortality, severe disability, and upper severe disability. Compared with the DECRA trial, patients in this most recent study underwent DC as the last tier in the algorithm for management of refractory ICH. Patients with mass lesions were included as well as those who underwent unilateral decompression. Similar to the DECRA RCT, the RESCUEicp showed increased disability among survivors. ${ }^{69}$

\section{Abdominal Decompression}

The differential for intracranial hypertension should also include intraabdominal hypertension or abdominal compartment syndrome, in particular those subject to large volume resuscitations and/or polytrauma patients. ${ }^{70}$ Monitoring serial bladder pressures with possible paralysis may assist with the diagnosis. Abdominal decompression in patients with elevated ICP refractory to medical management with concomitant intra-abdominal hypertension has been shown to be efficacious in lowering ICP and should be considered in this patient group. ${ }^{71,72}$

\section{Hypothermia}

Hypothermia has been investigated as a means of neuroprotection following TBI. A systemic review of randomized controlled trials of hypothermia in traumatic brain injury found that hypothermia was associated with reduced mortality and improvements in neurologic function. ${ }^{73}$ Other authors call into question the benefits of hypothermia in TBI citing poor quality trials. ${ }^{74}$ The BTF currently recommends against the routine use of early, short term prophylactic hypothermia in patients with diffuse TBI. ${ }^{30}$

\section{ICU Management: Venous Thromboembolism Prophylaxis}

Patients with traumatic brain injury are at risk for venous thromboembolic disease given venous stasis, venous injury, and potential coagulopathy associated with TBI.

Pharmacologic agents are often withheld in the initial post-injury period over concerns for worsening of an intracranial bleed. A study from 2011 by Scudday, et. al. looked at 812 head injured patients, about half of whom received pharmacologic prophylaxis (the majority with heparin). Forty percent of patients received prophylaxis within 48 hours with an average start time of 96 hours after hospital arrival. Patients who received pharmacologic prophylaxis had a lower incidence of VTE compared to those who did not (1\% vs. 3\%). Interestingly, there was also a trend toward lower incidence of worsening hemorrhage in the 
treatment group, although it is important to note that VTE diagnosis in that study was based on clinical symptoms and asymptomatic VTE may have been more prevalent. ${ }^{75}$

A review by Phelan in 2012 presents a protocol whereby those with "low risk" TBI can be started on enoxaparin within 24 hours post injury, those with "moderate risk" TBI based on specified imaging characteristics can be started after 72 hours, and those with "high risk" TBI should undergo IVC filter placement. ${ }^{76}$ The BTF recommends pharmacologic DVT prophylaxis if the injury is "stable" and the benefits of prophylaxis outweighs the risks of hemorrhage progression. There are no recommendations regarding timing, dose, or agent. ${ }^{30}$ Local culture along with input from neurosurgery colleagues may help to dictate the approach to anticoagulation in these patients as well.

\section{ICU Management: Stress Ulcer Prophylaxis}

Head injury has been associated with increased gastric acid secretion. Both proton pump inhibitors (PPI) and histamine-2 receptor antagonists $\left(\mathrm{H}_{2}\right)$ have been shown to reduce the incidence of upper gastrointestinal bleeding in trauma and neurocritical care patients. ${ }^{77-79} \mathrm{In}$ a review of the literature involving neurological and neurosurgical intensive care unit patients, $\mathrm{H}_{2}$ blockers were found to be associated with increased rates of pneumonia, drug interactions, and coagulopathy, calling into question the role of these agents in TBI patients. ${ }^{78}$ In one recent study looking at mechanically ventilated critical care patients, including a small number of patients with intracerebral hemorrhage, PPI were associated with increased rates of pneumonia, clostridium difficile infection, and gastrointestinal hemorrhage. ${ }^{80}$ These data suggest a role for future prospective studies evaluating the ideal prophylaxis in severe TBI patients.

\section{ICU Management: Seizure Prophylaxis}

Early studies showed the benefit of phenytoin in the prevention of early post traumatic seizures (i.e., seizures within the first week after injury). However, early prophylaxis with antiepileptics has not been showed to improve late post-traumatic seizures (i.e., $>7$ days post-injury), mortality, or neurologic function. ${ }^{81}$ The 2016 BTF guidelines recommend that phenytoin to decrease early post-traumatic seizures when the risk-benefit favors treatment. ${ }^{30}$

Studies comparing levetiracetam and phenytoin have shown that levetiracetam is as effective at reducing early seizures and is an attractive alternative given it does not require serum monitoring, is less expensive, and has less drug-drug interactions. ${ }^{82-84}$ Although the BTF currently outlines insufficient evidence to recommend levetiracetam over phenytoin, our practice is to use levetiracetam ( $1000 \mathrm{mg}$ bolus followed by $500 \mathrm{mg}$ IV/PO BID for 7 days with renal adjustment if needed) for patients with any structural intracranial injury on cross sectional imaging. We also consider omission of seizure prophylaxis if patients are older than 65 with good neurologic function.

\section{Nutrition}

Early enteral nutrition (EN) has been shown to have a beneficial effect in many patient populations, including those with TBI. A study by Hartle, et. al found that patients who were 
not fed within the first week after TBI had significant increases in mortality, even when controlled for other factors known to affect outcome. ${ }^{85}$ Early "enhanced" EN, where goal feeds are reached on day 1 of injury, has also showed benefit over more traditional EN in terms of infectious and overall complications and possibly even longer term outcomes out to three months post injury. ${ }^{86}$ Other studies have shown that EN within 48 hours is associated with improved survival and neurologic outcome in severely head injured patients. ${ }^{87}$ There is some evidence that transpyloric feeding is associated with decreased pneumonia and is more efficacious in patients with TBI compared to the gastric route. ${ }^{88}$ Achieving adequate caloric intake by day 7 and transgastric jejunal feeding is currently supported by the BTF guidelines.

\section{ICU Management: Other Therapies}

Results of the CRASH trial do not support use of corticosteroids in head injured patients. ${ }^{89,90}$ Intensive insulin therapy $(80-120 \mathrm{mg} / \mathrm{dl})$ in TBI patients has been associated with less infectious complications and shorter ICU length of stay compared with a less aggressive strategy $(<220 \mathrm{mg} / \mathrm{dl})$, but was associated with more hypoglycemia and similar outcomes and infectious complications and has not generated strong clinical enthusiasm. ${ }^{91}$ In two large multicenter randomized clinical trials, administration of intravenous progesterone also failed to show a clinical benefit in humans. ${ }^{92,93}$ Previous work has shown an association between beta-blockade and improvement in mortality after TBI in humans and improvement in cerebral blood flow in mice. ${ }^{94,95}$ There are currently trials underway to assess the effect of adrenergic and sympathetic blockade on outcomes after TBI (NCT01322048 and NCT02957331). ${ }^{96}$

\section{Summary}

Traumatic brain injury is a leading cause of death and disability in trauma patients. The rapid transfer of TBI patients to trauma centers and the avoidance of secondary insults such as hypotension and hypoxia are paramount. Elevated ICP should be managed in an algorithmic fashion utilizing simple beside maneuvers, hyperosmolar agents, ventricular drainage, barbiturates, and operative intervention when appropriate. Nutritional status should be optimized and the clinician should focus on prophylaxis against stress ulceration, early seizures, and venous thromboemboli. The role of novel techniques to measure cerebral blood flow and oxygenation is still being elucidated.

\section{Acknowledgments}

Funding Sources: MBP is supported by National Institutes of Health (Bethesda, MD) NHLBI R01 HL111111 and NIGMS R01 GM120484. This work was also supported by REDCap UL1 TR000445 from NCATS/NIH.

\section{References}

1. Langlois JA, Rutland-Brown W, Wald MM. The epidemiology and impact of traumatic brain injury: a brief overview. J Head Trauma Rehabil. 2006; 21(5):375-378. [PubMed: 16983222]

2. Stocchetti N, Maas AI. Traumatic intracranial hypertension. N Engl J Med. 2014; 371(10):972. [PubMed: 25184881]

3. CDC Website. 
4. Crandall.

5. Guillamondegui MBPOD. Traumatic brain injury, severe: medical and surgical management. 1. Verlag Berline Heidelberg; Springer: 2015.

6. Werner C, Engelhard K. Pathophysiology of traumatic brain injury. Br J Anaesth. 2007; 99(1):4-9. [PubMed: 17573392]

7. Chesnut RM, Marshall LF, Klauber MR, et al. The role of secondary brain injury in determining outcome from severe head injury. J Trauma. 1993; 34(2):216-222. [PubMed: 8459458]

8. Jeremitsky E, Omert L, Dunham CM, Protetch J, Rodriguez A. Harbingers of poor outcome the day after severe brain injury: hypothermia, hypoxia, and hypoperfusion. J Trauma. 2003; 54(2):312319. [PubMed: 12579057]

9. Miller JD, Sweet RC, Narayan R, Becker DP. Early insults to the injured brain. JAMA. 1978; 240(5):439-442. [PubMed: 660888]

10. Chi JH, Knudson MM, Vassar MJ, et al. Prehospital hypoxia affects outcome in patients with traumatic brain injury: a prospective multicenter study. J Trauma. 2006; 61(5):1134-1141. [PubMed: 17099519]

11. Davis DP, Hoyt DB, Ochs M, et al. The effect of paramedic rapid sequence intubation on outcome in patients with severe traumatic brain injury. J Trauma. 2003; 54(3):444-453. [PubMed: 12634522]

12. Cooper DJ, Myles PS, McDermott FT, et al. Prehospital hypertonic saline resuscitation of patients with hypotension and severe traumatic brain injury: a randomized controlled trial. JAMA. 2004; 291(11):1350-1357. [PubMed: 15026402]

13. Bulger EM, May S, Brasel KJ, et al. Out-of-hospital hypertonic resuscitation following severe traumatic brain injury: a randomized controlled trial. JAMA. 2010; 304(13):1455-1464. [PubMed: 20924011]

14. ATLS Book.

15. Zeiler FA, Teitelbaum J, West M, Gillman LM. The ketamine effect on ICP in traumatic brain injury. Neurocrit Care. 2014; 21(1):163-173. [PubMed: 24515638]

16. Imberti R, Bellinzona G, Langer M. Cerebral tissue $\mathrm{PO} 2$ and $\mathrm{SjvO} 2$ changes during moderate hyperventilation in patients with severe traumatic brain injury. J Neurosurg. 2002; 96(1):97-102. [PubMed: 11794610]

17. Marion DW, Puccio A, Wisniewski SR, et al. Effect of hyperventilation on extracellular concentrations of glutamate, lactate, pyruvate, and local cerebral blood flow in patients with severe traumatic brain injury. Crit Care Med. 2002; 30(12):2619-2625. [PubMed: 12483048]

18. Thomas SH, Orf J, Wedel SK, Conn AK. Hyperventilation in traumatic brain injury patients: inconsistency between consensus guidelines and clinical practice. J Trauma. 2002; 52(1):47-52. discussion 52-43. [PubMed: 11791051]

19. Cohen MJ, Brohi K, Ganter MT, Manley GT, Mackersie RC, Pittet JF. Early coagulopathy after traumatic brain injury: the role of hypoperfusion and the protein C pathway. J Trauma. 2007; 63(6):1254-1261. discussion 1261-1252. [PubMed: 18212647]

20. Holcomb JB, Tilley BC, Baraniuk S, et al. Transfusion of plasma, platelets, and red blood cells in a 1:1:1 vs a 1:1:2 ratio and mortality in patients with severe trauma: the PROPPR randomized clinical trial. JAMA. 2015; 313(5):471-482. [PubMed: 25647203]

21. Stein SC, Smith DH. Coagulopathy in traumatic brain injury. Neurocrit Care. 2004; 1(4):479-488. [PubMed: 16174954]

22. Barbosa RR, Jawa R, Watters JM, et al. Evaluation and management of mild traumatic brain injury: an Eastern Association for the Surgery of Trauma practice management guideline. J Trauma Acute Care Surg. 2012; 73(5 Suppl 4):S307-314. [PubMed: 23114486]

23. Smits M, Dippel DW, de Haan GG, et al. External validation of the Canadian CT Head Rule and the New Orleans Criteria for CT scanning in patients with minor head injury. JAMA. 2005; 294(12):1519-1525. [PubMed: 16189365]

24. Bullock MR, Chesnut R, Ghajar J, et al. Surgical management of acute epidural hematomas. Neurosurgery. 2006; 58(3 Suppl):7-15. discussion Si-iv.

25. Current Surgical Therapy. 
26. Bullock MR, Chesnut R, Ghajar J, et al. Surgical management of traumatic parenchymal lesions. Neurosurgery. 2006; 58(3 Suppl):S25-46. discussion Si-iv. [PubMed: 16540746]

27. Seelig JM, Becker DP, Miller JD, Greenberg RP, Ward JD, Choi SC. Traumatic acute subdural hematoma: major mortality reduction in comatose patients treated within four hours. N Engl J Med. 1981; 304(25):1511-1518. [PubMed: 7231489]

28. Wilberger JE Jr, Harris M, Diamond DL. Acute subdural hematoma: morbidity, mortality, and operative timing. J Neurosurg. 1991; 74(2):212-218. [PubMed: 1988590]

29. Mendelow AD, Gregson BA, Rowan EN, et al. Early Surgery versus Initial Conservative Treatment in Patients with Traumatic Intracerebral Hemorrhage (STITCH[Trauma]): The First Randomized Trial. J Neurotrauma. 2015; 32(17):1312-1323. [PubMed: 25738794]

30. Carney N, Totten AM, O'Reilly C, et al. Guidelines for the Management of Severe Traumatic Brain Injury, Fourth Edition. Neurosurgery. 2016

31. Feinstein AJ, Patel MB, Sanui M, Cohn SM, Majetschak M, Proctor KG. Resuscitation with pressors after traumatic brain injury. J Am Coll Surg. 2005; 201(4):536-545. [PubMed: 16183491]

32. Investigators SS, Australian, New Zealand Intensive Care Society Clinical Trials G. Saline or albumin for fluid resuscitation in patients with traumatic brain injury. N Engl J Med. 2007; 357(9): 874-884. [PubMed: 17761591]

33. Robertson CS, Hannay HJ, Yamal JM, et al. Effect of erythropoietin and transfusion threshold on neurological recovery after traumatic brain injury: a randomized clinical trial. JAMA. 2014; 312(1):36-47. [PubMed: 25058216]

34. Grandhi R, Harrison G, Voronovich Z, et al. Preinjury warfarin, but not antiplatelet medications, increases mortality in elderly traumatic brain injury patients. J Trauma Acute Care Surg. 2015; 78(3):614-621. [PubMed: 25710435]

35. Mina AA, Knipfer JF, Park DY, Bair HA, Howells GA, Bendick PJ. Intracranial complications of preinjury anticoagulation in trauma patients with head injury. J Trauma. 2002; 53(4):668-672. [PubMed: 12394864]

36. Pieracci FM, Eachempati SR, Shou J, Hydo LJ, Barie PS. Degree of anticoagulation, but not warfarin use itself, predicts adverse outcomes after traumatic brain injury in elderly trauma patients. J Trauma. 2007; 63(3):525-530. [PubMed: 18073596]

37. Calland JF, Ingraham AM, Martin N, et al. Evaluation and management of geriatric trauma: an Eastern Association for the Surgery of Trauma practice management guideline. J Trauma Acute Care Surg. 2012; 73(5 Suppl 4):S345-350. [PubMed: 23114492]

38. Ivascu FA, Howells GA, Junn FS, Bair HA, Bendick PJ, Janczyk RJ. Rapid warfarin reversal in anticoagulated patients with traumatic intracranial hemorrhage reduces hemorrhage progression and mortality. J Trauma. 2005; 59(5):1131-1137. discussion 1137-1139. [PubMed: 16385291]

39. McMillian WD, Rogers FB. Management of prehospital antiplatelet and anticoagulant therapy in traumatic head injury: a review. J Trauma. 2009; 66(3):942-950. [PubMed: 19276776]

40. Matsushima K, Benjamin E, Demetriades D. Prothrombin complex concentrate in trauma patients. Am J Surg. 2015; 209(2):413-417. [PubMed: 25457236]

41. Joseph B, Hadjizacharia P, Aziz H, et al. Prothrombin complex concentrate: an effective therapy in reversing the coagulopathy of traumatic brain injury. J Trauma Acute Care Surg. 2013; 74(1):248253. [PubMed: 23271101]

42. Beynon C, Hertle DN, Unterberg AW, Sakowitz OW. Clinical review: Traumatic brain injury in patients receiving antiplatelet medication. Crit Care. 2012; 16(4):228. [PubMed: 22839302]

43. Siegal DM, Cuker A. Reversal of novel oral anticoagulants in patients with major bleeding. J Thromb Thrombolysis. 2013; 35(3):391-398. [PubMed: 23389753]

44. Pollack CV Jr, Reilly PA, Eikelboom J, et al. Idarucizumab for Dabigatran Reversal. N Engl J Med. 2015; 373(6):511-520. [PubMed: 26095746]

45. Shakur H, Roberts I, et al. collaborators C-t. Effects of tranexamic acid on death, vascular occlusive events, and blood transfusion in trauma patients with significant haemorrhage (CRASH-2): a randomised, placebo-controlled trial. Lancet. 2010; 376(9734):23-32. [PubMed: 20554319] 
46. Crash-2 Collaborators IBS. Effect of tranexamic acid in traumatic brain injury: a nested randomised, placebo controlled trial (CRASH-2 Intracranial Bleeding Study). BMJ. 2011; 343:d3795. [PubMed: 21724564]

47. Dewan Y, Komolafe EO, Mejia-Mantilla JH, et al. CRASH-3 - tranexamic acid for the treatment of significant traumatic brain injury: study protocol for an international randomized, double-blind, placebo-controlled trial. Trials. 2012; 13:87. [PubMed: 22721545]

48. Joseph B, Aziz H, Sadoun M, et al. The acute care surgery model: managing traumatic brain injury without an inpatient neurosurgical consultation. J Trauma Acute Care Surg. 2013; 75(1):102-105. discussion 105. [PubMed: 23778447]

49. Feldman Z, Kanter MJ, Robertson CS, et al. Effect of head elevation on intracranial pressure, cerebral perfusion pressure, and cerebral blood flow in head-injured patients. J Neurosurg. 1992; 76(2):207-211. [PubMed: 1730949]

50. Kasotakis G, Michailidou M, Bramos A, et al. Intraparenchymal vs extracranial ventricular drain intracranial pressure monitors in traumatic brain injury: less is more? J Am Coll Surg. 2012; 214(6):950-957. [PubMed: 22541986]

51. Nwachuku EL, Puccio AM, Fetzick A, et al. Intermittent versus continuous cerebrospinal fluid drainage management in adult severe traumatic brain injury: assessment of intracranial pressure burden. Neurocrit Care. 2014; 20(1):49-53. [PubMed: 23943318]

52. Tisdall MM, Smith M. Multimodal monitoring in traumatic brain injury: current status and future directions. Br J Anaesth. 2007; 99(1):61-67. [PubMed: 17548431]

53. Juul N, Morris GF, Marshall SB, Marshall LF. Intracranial hypertension and cerebral perfusion pressure: influence on neurological deterioration and outcome in severe head injury. The Executive Committee of the International Selfotel Trial. J Neurosurg. 2000; 92(1):1-6.

54. Talving P, Karamanos E, Teixeira PG, et al. Intracranial pressure monitoring in severe head injury: compliance with Brain Trauma Foundation guidelines and effect on outcomes: a prospective study. J Neurosurg. 2013; 119(5):1248-1254. [PubMed: 23971954]

55. Farahvar A, Gerber LM, Chiu YL, Carney N, Hartl R, Ghajar J. Increased mortality in patients with severe traumatic brain injury treated without intracranial pressure monitoring. J Neurosurg. 2012; 117(4):729-734. [PubMed: 22900846]

56. Chesnut RM, Temkin N, Carney N, et al. A Trial of Intracranial-Pressure Monitoring in Traumatic Brain Injury. New Engl J Med. 2012; 367(26):2471-2481. [PubMed: 23234472]

57. Bouzat P, Sala N, Payen JF, Oddo M. Beyond intracranial pressure: optimization of cerebral blood flow, oxygen, and substrate delivery after traumatic brain injury. Ann Intensive Care. 2013; 3(1): 23. [PubMed: 23837598]

58. Prabhakar H, Sandhu K, Bhagat H, Durga P, Chawla R. Current concepts of optimal cerebral perfusion pressure in traumatic brain injury. J Anaesthesiol Clin Pharmacol. 2014; 30(3):318-327. [PubMed: 25190937]

59. Robertson CS, Gopinath SP, Goodman JC, Contant CF, Valadka AB, Narayan RK. SjvO2 monitoring in head-injured patients. J Neurotrauma. 1995; 12(5):891-896. [PubMed: 8594216]

60. Stocchetti N, Canavesi K, Magnoni S, et al. Arterio-jugular difference of oxygen content and outcome after head injury. Anesth Analg. 2004; 99(1):230-234. [PubMed: 15281535]

61. Robertson C. Desaturation episodes after severe head injury: influence on outcome. Acta Neurochir Suppl (Wien). 1993; 59:98-101. [PubMed: 8310869]

62. Mangat HS, Chiu YL, Gerber LM, Alimi M, Ghajar J, Hartl R. Hypertonic saline reduces cumulative and daily intracranial pressure burdens after severe traumatic brain injury. J Neurosurg. 2015; 122(1):202-210. [PubMed: 25380107]

63. Marshall GT, James RF, Landman MP, et al. Pentobarbital coma for refractory intracranial hypertension after severe traumatic brain injury: mortality predictions and one-year outcomes in 55 patients. J Trauma. 2010; 69(2):275-283. [PubMed: 20699736]

64. Roberts I, Sydenham E. Barbiturates for acute traumatic brain injury. Cochrane Database Syst Rev. 2012; 12:CD000033. [PubMed: 23235573]

65. Eisenberg HM, Frankowski RF, Contant CF, Marshall LF, Walker MD. High-dose barbiturate control of elevated intracranial pressure in patients with severe head injury. J Neurosurg. 1988; 69(1):15-23. [PubMed: 3288723] 
66. Bor-Seng-Shu E, Figueiredo EG, Amorim RL, et al. Decompressive craniectomy: a metaanalysis of influences on intracranial pressure and cerebral perfusion pressure in the treatment of traumatic brain injury. J Neurosurg. 2012; 117(3):589-596. [PubMed: 22794321]

67. Weiner GM, Lacey MR, Mackenzie L, et al. Decompressive craniectomy for elevated intracranial pressure and its effect on the cumulative ischemic burden and therapeutic intensity levels after severe traumatic brain injury. Neurosurgery. 2010; 66(6):1111-1118. discussion 1118-1119. [PubMed: 20386136]

68. Cooper DJ, Rosenfeld JV, Murray L, et al. Decompressive craniectomy in diffuse traumatic brain injury. N Engl J Med. 2011; 364(16):1493-1502. [PubMed: 21434843]

69. Hutchinson PJ, Kolias AG, Timofeev IS, et al. Trial of Decompressive Craniectomy for Traumatic Intracranial Hypertension. N Engl J Med. 2016; 375(12):1119-1130. [PubMed: 27602507]

70. Kirkpatrick AW, Roberts DJ, De Waele J, et al. Intra-abdominal hypertension and the abdominal compartment syndrome: updated consensus definitions and clinical practice guidelines from the World Society of the Abdominal Compartment Syndrome. Intens Care Med. 2013; 39(7):11901206.

71. Dorfman JD, Burns JD, Green DM, DeFusco C, Agarwal S. Decompressive Laparotomy for Refractory Intracranial Hypertension After Traumatic Brain Injury. Neurocrit Care. 2011; 15(3): 516-518. [PubMed: 21519956]

72. Joseph DK, Dutton RP, Aarabi B, Scalea TM. Decompressive laparotomy to treat intractable intracranial hypertension after traumatic brain injury. J Trauma. 2004; 57(4):687-693. [PubMed: 15514520]

73. McIntyre LA, Fergusson DA, Hebert PC, Moher D, Hutchison JS. Prolonged therapeutic hypothermia after traumatic brain injury in adults: a systematic review. JAMA. 2003; 289(22): 2992-2999. [PubMed: 12799408]

74. Sydenham E, Roberts I, Alderson P. Hypothermia for traumatic head injury. Cochrane Database Syst Rev. 2009(2):CD001048.

75. Scudday T, Brasel K, Webb T, et al. Safety and efficacy of prophylactic anticoagulation in patients with traumatic brain injury. J Am Coll Surg. 2011; 213(1):148-153. discussion 153-144. [PubMed: 21459632]

76. Phelan HA. Pharmacologic venous thromboembolism prophylaxis after traumatic brain injury: a critical literature review. J Neurotrauma. 2012; 29(10):1821-1828. [PubMed: 22651698]

77. Halloran LG, Zfass AM, Gayle WE, Wheeler CB, Miller JD. Prevention of Acute Gastrointestinal Complications after Severe Head-Injury - Controlled Trial of Cimetidine Prophylaxis. Am J Surg. 1980; 139(1):44-48. [PubMed: 6985776]

78. Schirmer CM, Kornbluth J, Heilman CB, Bhardwaj A. Gastrointestinal prophylaxis in neurocritical care. Neurocrit Care. 2012; 16(1):184-193. [PubMed: 21748505]

79. Lasky MR, Metzler MH, Phillips JO. A prospective study of omeprazole suspension to prevent clinically significant gastrointestinal bleeding from stress ulcers in mechanically ventilated trauma patients. J Trauma. 1998; 44(3):527-533. [PubMed: 9529184]

80. MacLaren R, Reynolds PM, Allen RR. Histamine-2 receptor antagonists vs proton pump inhibitors on gastrointestinal tract hemorrhage and infectious complications in the intensive care unit. JAMA Intern Med. 2014; 174(4):564-574. [PubMed: 24535015]

81. Temkin NR, Dikmen SS, Wilensky AJ, Keihm J, Chabal S, Winn HR. A randomized, double-blind study of phenytoin for the prevention of post-traumatic seizures. N Engl J Med. 1990; 323(8):497502. [PubMed: 2115976]

82. Inaba K, Menaker J, Branco BC, et al. A prospective multicenter comparison of levetiracetam versus phenytoin for early posttraumatic seizure prophylaxis. J Trauma Acute Care. 2013; 74(3): 766-771.

83. Jones KE, Puccio AM, Harshman KJ, et al. Levetiracetam versus phenytoin for seizure prophylaxis in severe traumatic brain injury. Neurosurg Focus. 2008; 25(4):E3.

84. Szaflarski JP, Sangha KS, Lindsell CJ, Shutter LA. Prospective, randomized, single-blinded comparative trial of intravenous levetiracetam versus phenytoin for seizure prophylaxis. Neurocrit Care. 2010; 12(2):165-172. [PubMed: 19898966] 
85. Hartl R, Gerber LM, Ni Q, Ghajar J. Effect of early nutrition on deaths due to severe traumatic brain injury. J Neurosurg. 2008; 109(1):50-56. [PubMed: 18590432]

86. Taylor SJ, Fettes SB, Jewkes C, Nelson RJ. Prospective, randomized, controlled trial to determine the effect of early enhanced enteral nutrition on clinical outcome in mechanically ventilated patients suffering head injury. Crit Care Med. 1999; 27(11):2525-2531. [PubMed: 10579275]

87. Chiang YH, Chao DP, Chu SF, et al. Early enteral nutrition and clinical outcomes of severe traumatic brain injury patients in acute stage: a multi-center cohort study. J Neurotrauma. 2012; 29(1):75-80. [PubMed: 21534720]

88. Acosta-Escribano J, Fernandez-Vivas M, Grau Carmona T, et al. Gastric versus transpyloric feeding in severe traumatic brain injury: a prospective, randomized trial. Intensive Care Med. 2010; 36(9):1532-1539. [PubMed: 20495781]

89. Edwards P, Arango M, Balica L, et al. Final results of MRC CRASH, a randomised placebocontrolled trial of intravenous corticosteroid in adults with head injury-outcomes at 6 months. Lancet. 2005; 365(9475):1957-1959. [PubMed: 15936423]

90. Roberts I, Yates D, Sandercock P, et al. Effect of intravenous corticosteroids on death within 14 days in 10008 adults with clinically significant head injury (MRC CRASH trial): randomised placebo-controlled trial. Lancet. 2004; 364(9442):1321-1328. [PubMed: 15474134]

91. Bilotta F, Caramia R, Cernak I, et al. Intensive insulin therapy after severe traumatic brain injury: a randomized clinical trial. Neurocrit Care. 2008; 9(2):159-166. [PubMed: 18373223]

92. Skolnick BE, Maas AI, Narayan RK, et al. A clinical trial of progesterone for severe traumatic brain injury. N Engl J Med. 2014; 371(26):2467-2476. [PubMed: 25493978]

93. Wright DW, Yeatts SD, Silbergleit R, et al. Very Early Administration of Progesterone for Acute Traumatic Brain Injury. New Engl J Med. 2014; 371(26):2457-2466. [PubMed: 25493974]

94. Cotton BA, Snodgrass KB, Fleming SB, et al. Beta-blocker exposure is associated with improved survival after severe traumatic brain injury. J Trauma. 2007; 62(1):26-33. discussion 33-25. [PubMed: 17215730]

95. Ley EJ, Scehnet J, Park R, et al. The in vivo effect of propranolol on cerebral perfusion and hypoxia after traumatic brain injury. J Trauma. 2009; 66(1):154-159. discussion 159-161. [PubMed: 19131818]

96. Patel MB, McKenna JW, Alvarez JM, et al. Decreasing adrenergic or sympathetic hyperactivity after severe traumatic brain injury using propranolol and clonidine (DASH After TBI Study): study protocol for a randomized controlled trial. Trials. 2012; 13:177. [PubMed: 23013802] 


\section{Key Points}

1. Traumatic brain injury (TBI) is a leading cause of death and disability in trauma patients with a significant economic impact.

2. The acute management of TBI focuses on the prevention of secondary injury through the avoidance of hypotension and hypoxia and maintenance of appropriate cerebral perfusion pressure (CPP) and, by extension, cerebral blood flow (CBF).

3. Mass lesions may require operative intervention based on imaging characteristic, exam findings, and measurements of intracranial pressure (ICP).

4. Elevated ICP can be managed in an algorithmic fashion utilizing a combination of simple bedside maneuvers, hyperosmolar therapy, cerebrospinal fluid (CSF) drainage, pentobarbital coma, and decompressive craniectomy.

5. Other important considerations in TBI patients include venous thromboembolism, stress ulcer, and seizure prophylaxis as well as nutrition and metabolic optimization. 


\section{Traumatic Brain Injury Pathway, GCS $<9$}

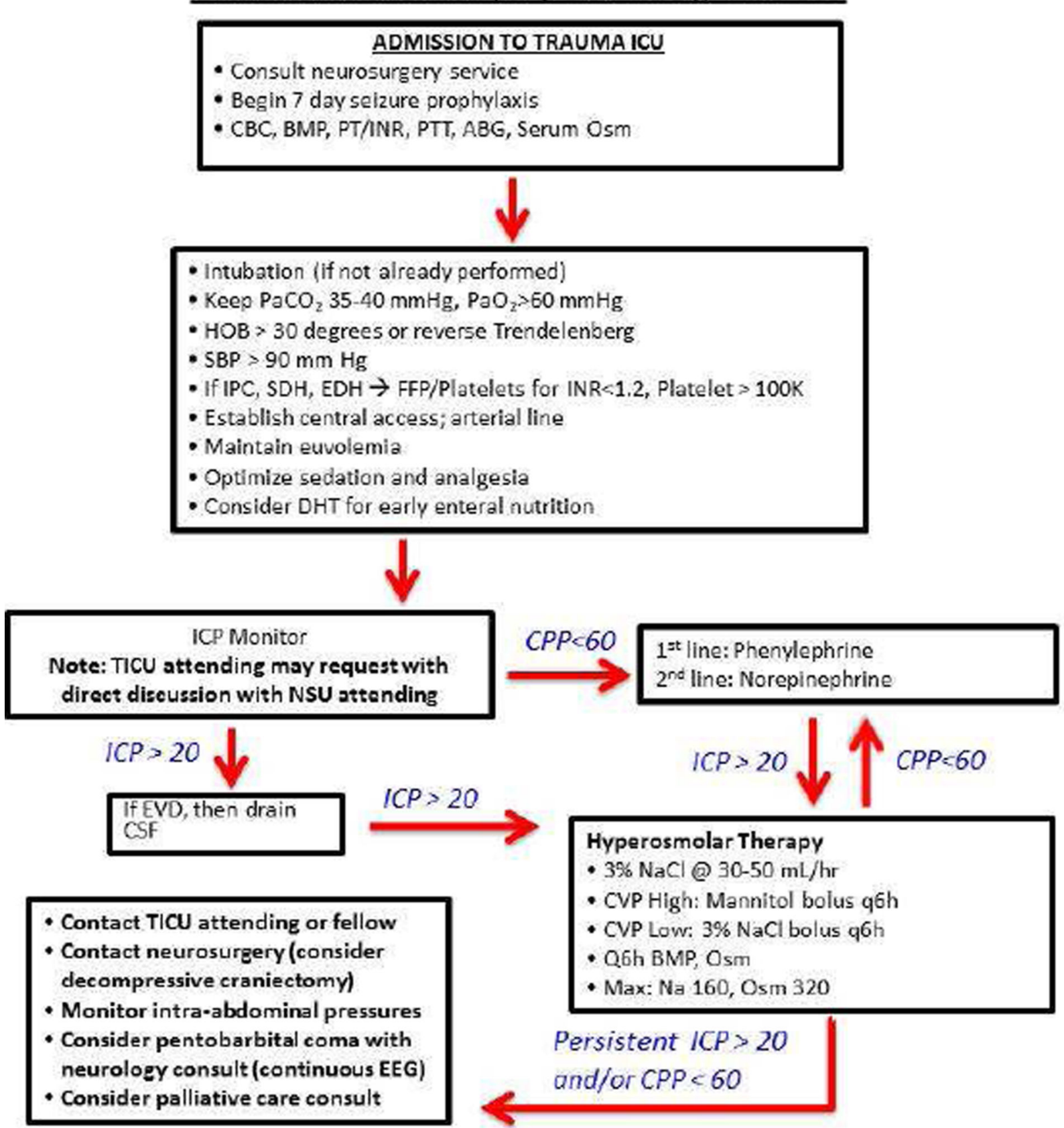

Figure 1.

Algorithmic Approach to the Management of Severe Traumatic Brain Injury (GCS <9) Simple algorithm for the management of severe head injury as described in the text. $\mathrm{CBC}=$ complete blood count; $\mathrm{BMP}=$ basic metabolic panel; $\mathrm{PT} / \mathrm{INR}=$ prothrombin time/ international normalized ratio; $\mathrm{PTT}=$ partial thromboplastin time; $\mathrm{ABG}=$ arterial blood gas; Osm=osmolality; $\mathrm{HOB}=$ head of bed; $\mathrm{SBP}=$ systolic blood pressure; $\mathrm{IPC}=$ intraparenchymal contusion; $\mathrm{EDH}=$ epidural hematoma; $\mathrm{SDH}=$ subdural hematoma; $\mathrm{FFP}=$ fresh frozen plasma; DHT=Dobhoff tube; ICP=intracranial pressure; TICU=trauma ICU; NSU=neurosurgery; 
$\mathrm{CPP}=$ cerebral perfusion pressure; $\mathrm{EVD}=$ extraventricular drain; $\mathrm{CSF}=$ cerebrospinalfluid;

$\mathrm{CVP}=$ central venous pressure; $\mathrm{NaCl}=$ sodium chloride; $\mathrm{Na}=$ sodium;

$\mathrm{EEG}=$ electroencephalogram 